\title{
Entre la competencia y la cooperación: la construcción de redes entre las Organizaciones No Gubernamentales de Desarrollo en Andalucía
}

Beltrán Roca Martínez - Universidad de Sevilla - Departamento Antropología Social ${ }^{1}$

\section{Resumen}

Las ONGD se encuentran en un espacio social cuyas «reglas del juego» les llevan a la paradoja de tener que competir por una serie de recursos en juego y cooperar para incidir sobre terceros. La Coordinadora Andaluza de ONGD (CAONGD), por tanto, se convierte en un escenario privilegiado para observar dichas dinámicas. Mediante un análisis de redes sociales entre las ONGD más activas de la coordinadora, describimos las estrategias de actuación de estas organizaciones y la construcción y circulación de significados a través de sus redes.

Palabras clave: ONG, redes sociales, cooperación al desarrollo.

\begin{abstract}
NGOD are situated in a social space whose «gambling rules» impose the paradox of having to compete for resources at stake and cooperate to influence on outsiders. The "Coordinadora Andaluza of NGOD" (CAONGD) is, therefore, a privileged stage to watch those dynamics. By means of a social networks analysis of the relationships behind the more active NGOD of such coordinating committee, we describe the strategies of those organizations and the construction and circulation of meanings through their networks.
\end{abstract}

Key words: NGO, social networks, cooperation for development.

\section{I ntroducción}

Desastres naturales que originan millares de víctimas, conflictos bélicos que obligan a desplazarse a grandes grupos de población, cumbres de organismos supranacionales ensombrecidas por fuertes enfrentamientos callejeros entre manifestantes y fuerzas de seguridad, etc. Dentro de la extendida controversia sobre la globalización y sus consecuencias, la cooperación al desarrollo y las ONGD (Organizaciones No Gubernamentales de Desarrollo) tienen un importante papel. Estas organizaciones están cobrando un gran protagonismo social tanto en los países "desarrollados" como en los países "en vías de desarrollo". En Andalucía existen alrededor de cien ONGD de muy diversas características, cuyas actividades tienen una importante repercusión sobre diferentes sectores de la sociedad.

\footnotetext{
${ }^{1}$ Enviar correspondencia a: Beltrán Roca Martínez, broca@us.es
} 
El auge de la doctrina neoliberal ha venido acompañado del desarrollo de un Tercer Sector que está complementando - cuando no sustituyendo- la acción estatal en materia de educación, sanidad, servicios sociales y ayuda al otro. Un estudio comparativo de la Universidad John Hopkins (Salomon, Anheier, et al, 1999) desvela que, en España, el sector no lucrativo constituye una fuerza económica en alza: en 1995 movilizó 22.600 millones de dólares -el 4\% del PIB. Además, constituye una importante fuente de empleo: ese mismo año contaba con 475.179 trabajadores remunerados a tiempo completo, superando en empleo a numerosos sectores como transportes, alimentación, metalurgia, industria textil o industria química. Todo ello sin incluir el voluntariado: 253.599 personas. Una de las principales áreas en las que se divide este sector no lucrativo es la cooperación al desarrollo.

Precisamente este considerable número de participantes en las entidades de voluntariado es una de las múltiples manifestaciones de las actuales transformaciones en las fórmulas de participación política. Las pulsiones participativas presentan dos tendencias complementarias: por un lado, tienden a centrarse en lo local y lo proxémico - la noción de socialidad de Maffesoli (1990) apunta en esta dirección; por otro lado, la afiliación más o menos estable a determinadas organizaciones está cediendo paso a la participación en los llamados Nuevos Movimientos Sociales de vida más efímera. Como señala Castells, la identidad y la localización constituyen elementos centrales en la articulación de los movimientos sociales (Castells: 2000). La “aparición" del «voluntariado» y la pérdida de peso de la «militancia» están estrechamente relacionados con esos cambios socio-culturales contemporáneos.

Basándonos en las aportaciones de Pierre Bourdieu, entendemos la cooperación al desarrollo como un campo social en el que operan diversos actores, entre ellos las ONGD. Las «reglas del juego» de este espacio social imponen a las ONG la paradójica necesidad de cooperar y competir. Las principales ONGD implantadas en Andalucía se encuentran federadas en la Coordinadora Andaluza de ONGD (CAONGD). Este texto constituye un análisis de las redes entre las ONGD más activas dentro de dicha federación. Nos interesan, por tanto, las relaciones entre los elementos estudiados, sus propiedades relacionales, y no tanto sus atributos individuales (Molina, 2001: 13). Partimos de la premisa de que para comprender las estrategias de actuación de dichas organizaciones, es preciso conocer cómo 
interactúan entre sí y cómo los significados se construyen y discurren a través de sus redes ${ }^{2}$.

\section{I. Sobre la visualización de redes sociales}

La utilización de imágenes como soporte de la actividad investigadora está a la orden del día en muchos campos de conocimiento científico. Desde las Ciencias Sociales se está a empleando de manera creciente la imagen (fotografía, video, sociogramas, etc.) tanto en el análisis de la realidad social como en la divulgación y transmisión de los resultados de obtenidos. En particular, la visualización de redes sociales, a pesar de sus limitaciones, puede resultar de gran ayuda para los antropólogos que pretendan comprender la configuración de dichas redes y comunicar a otros los resultados de su investigación (Freeman, 2000). La visualización es una actividad que realiza todo científico a lo largo de su investigación. En el caso del antropólogo, a medida que se sumerge en el trabajo de campo, va construyendo imágenes mentales sobre las estructuras de su objeto de estudio (organigrama formal o informal de una organización, redes sociales, sistemas de pensamiento, árboles genealógicos, etc.). Proyectar sobre el papel dichas visualizaciones ayuda a esclarecer cuestiones y a sistematizar la reflexión. Los avances y la proliferación de las tecnologías informáticas son de gran utilidad, existe una gran variedad de programas informáticos que permiten visualizar grandes redes sociales formadas por muchos nodos que de manera manual sería imposible representar.

\section{I I. Competencia y cooperación entre ONGD: el campo del desarrollo}

Inspirándonos en la teoría de los campos de Pierre Bourdieu (1991), podemos entender el mundo de la cooperación como un campo social, un espacio de correlaciones de fuerzas. En este mismo campo podemos distinguir diferentes aunque interrelacionadas- demarcaciones: la de las relaciones entre los actores individuales, profesionales y voluntarios, y la de las relaciones entre organizaciones. En este artículo nos centraremos en esta segunda demarcación.

\footnotetext{
2 Este trabajo forma parte de una investigación más amplia, bajo el título “Una aproximación antropológica a las ONGD en Andalucía", que estoy realizando en la Universidad de Sevilla, dentro del Grupo de Investigación GEISA (Grupo para el Estudio de las Identidades Socioculturales en Andalucía), código SEJ-149 del Plan Andaluz de Investigación, con la codirección del Catedrático de Antropología Social Isidoro Moreno Navarro y del Doctor Félix Talego Vázquez, y gracias al disfrute de una beca de Formación del Profesorado Universitario concedida por el Ministerio de Educación, Cultura y Deporte.
} 
Las organizaciones que intervienen en este espacio son de lo más variopintas: Estado, organizaciones internacionales y supraestatales, administraciones territoriales, empresas, partidos, universidades, Iglesias y sectas religiosas, sindicatos, ONGD, etc. Cada actor despliega diferentes estrategias de actuación en función de su posición y sus intereses. La finalidad de toda actuación es, según Bourdieu, la maximización del poder o capital en sus diferentes especies (económico, cultural, social y simbólico). El resultado de todo esto es una compleja maraña de relaciones entre esta multiplicidad de actores. En el caso de las ONGD las relaciones entre ellas son confusas y contradictorias. Si diésemos por válidos los objetivos formales de estas organizaciones (en términos generales, la erradicación de la pobreza), entre ellas tan sólo cabría esperar un tipo de relación: la cooperación. Sin embargo, la cuestión es mucho más complicada. Toda organización tiene una serie de fines oficiales y una serie de fines operativos (Perrow, 1961). Lo que es más, Michels (1996) sostiene que a lo largo de la vida de la organización hay una «sustitución de los fines», desde los oficiales hasta los operativos. Entre los fines operativos destaca siempre la supervivencia de la misma organización. Podemos afirmar que, como toda organización, las ONGD persiguen determinados fines operativos como la supervivencia o el crecimiento, que implican involucrarse de lleno en un sistema de relaciones de poder con todo tipo de organizaciones, incluidas aquellas con las que comparten los «fines oficiales». En esta línea, compartimos con Panebianco (1990: 15) el interés por privilegiar "la dimensión del poder en la organización", pero no sólo la estructura interna de poder, sino el sistema de alianzas y pugnas por el poder entre las diversas organizaciones que operan en un mismo espacio.

Aplicando todo esto a las relaciones inter-organizacionales de las ONGD, podemos afirmar que se encuentran forzadas a desenvolverse dentro de una situación paradójica: están obligadas a competir entre sí, pero, al mismo tiempo, necesitan cooperar para cumplir sus fines oficiales (puesto que, salvo contadas excepciones, éstos continúan teniendo una alta importancia). La lucha entre las ONGD se produce por la obtención de determinados recursos: fondos públicos, donaciones privadas, socios, voluntarios, atención en los medios de comunicación, reconocimiento social, representación ante órganos políticos, etc. El ejemplo más claro es el procedimiento establecido para obtener subvenciones. Una entidad pública o privada realiza una convocatoria y diversas ONGD compiten por que sus proyectos sean seleccionados. Obtener esta financiación requiere un capital cultural (conocimiento adecuado para diseñar de manera técnicamente correcta el proyecto), capital social (las relaciones de amistad, políticas, etc., con las 
instituciones suelen ser importantes), capital económico (generalmente la ONGD debe aportar una proporción del dinero del proyecto ${ }^{3}$ ) y capital simbólico (el prestigio de la ONGD también es muy importante ${ }^{4}$ ). Es en esta lucha de poder donde se produce la fragmentación entre organizaciones en función de variables ideológicas: al competir por unos recursos limitados las alianzas se generan con las ONGD ideológicamente afines. La rivalidad y el enfrentamiento son una parte sustancial de las relaciones inter-organizacionales de este tipo de entidades.

En cambio, frente a terceros las ONGD pretenden ofrecer una imagen unitaria y coherente (lo cual no siempre es posible). Todas las ONG comparten unos mismos fines explícitos y una serie de creencias que los ubican en unas posiciones más o menos homogéneas frente a otros actores sociales como los gobiernos, las administraciones, las grandes empresas, los organismos supranacionales, etc. Todo ello les lleva a coordinarse y aunar esfuerzos en federaciones, plataformas, redes y campañas conjuntas, a pesar verse forzadas a luchar por estos recursos. Las ONG otorgan una gran importancia al «trabajo en red». Hay una elevada profusión de federaciones, coordinadoras, plataformas, redes, etc. a distintos niveles. Por poner un ejemplo, la ONGD más conocida en el estado español, Intermón Oxfam, pertenece a:

OXFAM Internacional, CONGDE, EURODAD (Red Europea de Deuda y Desarrollo), Consejo Económico y Social de Naciones Unidas, EFTA (Asociación Europea de Organizaciones de Comercio Justo); IFAT (Federación Nacional de Comercio Justo); NEWS (Red Europea de Tiendas de Comercio Justo); Federaciones Autonómicas de ONG, AEMO (Asociación Española de Marketing Directo) y Coordinadora Catalana de Fundaciones (...). Intermón Oxfam justifica la pertenencia a estas redes porque esto posibilita sumar esfuerzos, y que este trabajo beneficie a más personas" (Fundación Lealtad 2003).

Una de las limitaciones que presenta el marco de análisis de Bourdieu es que traza unas fronteras y divisiones excesivamente rígidas entre los distintos campos que identifica. ¿Es la cooperación al desarrollo un campo autónomo? ¿Pertenece acaso al campo político? ¿Y al económico? ¿No intervienen acaso numerosos actores del

\footnotetext{
${ }^{3}$ Se han dado casos en que a una ONGD le han aprobado un proyecto y no ha podido ejecutarlo por no disponer de ese porcentaje de recursos económicos que se le exigían.

${ }^{4}$ El prestigio de una ONGD se genera a través de las estrategias de "marketing social", actividades visibles en las sociedades del norte (como la educación para el desarrollo), la transparencia (por ejemplo, mediante los informes de la Fundación Lealtad) y el reconocimiento oficial (ser declarada de utilidad pública, premios de instituciones, etc.) .
} 
campo religioso? Los límites del campo del desarrollo -y de los demás campos- son borrosos, inestables y fluidos. No obstante, lo que nos interesa de las aportaciones de Bourdieu es precisamente lo que ocurre dentro de los campos sociales, aunque la delimitación de ese campo no esté clara.

A lo largo de la investigación hemos encontrado cerca de un centenar de ONGD implantadas en el territorio andaluz. La mayor parte son delegaciones territoriales de organizaciones de ámbito estatal e internacional, algunas de ámbito local y otras, las menos, propiamente andaluzas. Muchas de estas organizaciones tienen un número muy reducido de socios y su actividad es relativamente escasa, lo que no descarta que en algunos casos sus delegaciones en otras comunidades autónomas sean más fuertes y activas. También es posible que algunas organizaciones hayan sido muy activas en un momento dado y en la actualidad se encuentren en un periodo de letargo o al borde de la desaparición. Las ONGD de más peso en Andalucía están adheridas a la Coordinadora Andaluza de Organizaciones No Gubernamentales (CAONGD). En la actualidad hay 45 organizaciones inscritas y dos en proceso de incorporación. Nos centraremos en las relaciones entre las ONGD más activas de la CAONGD. Por “organizaciones más activas" entiendo, aquellas que participan regularmente en las asambleas periódicas y forman parte de los diferentes grupos de trabajo que hay constituidos.

Hay que constatar que no todas las ONGD implantadas en Andalucía están federadas en dicha coordinadora: algunas consideran suficiente estar federadas en la Coordinadora Española de ONGD (por ejemplo, Cáritas), otras sencillamente no están interesadas en trabajar junto a otras organizaciones sociales y otras puede que no compartan algunos de los principios de la CAONGD o no suscriban su código de conducta.

La información sobre las relaciones entre las ONG proviene de diversas fuentes, las cuales hemos tratado de triangular en la medida de lo posible. Nuestra intención ha sido preguntar a un representante de cada organización con qué otras ONGD implantadas en Andalucía habían trabajado conjuntamente. Pensamos que el trabajo conjunto puede ser un indicador válido de la existencia de relaciones estrechas entre dos o más organizaciones. Como este análisis de redes sociales forma parte de una investigación de mayor alcance, aprovechamos para incluir esta pregunta al modelo de cuestionario de las "entrevistas abiertas semi-directivas". Mediante entrevistas obtuve información de 12 organizaciones. Posteriormente, enviamos un e-mail con la pregunta a las delegaciones en Andalucía del resto de ONGD más activas de la CAONGD, al que tan sólo respondieron 5. Finalmente, 
llamamos por teléfono a las 13 organizaciones que no respondieron la pregunta vía correo electrónico para completar la información. Triangulamos los resultados obtenidos con otras fuentes como la observación, la preguntas a terceros o la consulta de fuentes documentales. Por ejemplo, al ir a las sedes de las ONGD a realizar las entrevistas, solían coincidir las ONGD con que afirmaban haber trabajado conjuntamente, con las ONGD que habían elaborado panfletos, boletines, carteles y demás documentos que se exhibían en mostradores de la organización. Así mismo, en la medida en que nos íbamos sumergiendo en esta realidad y conociendo a los responsables de cada organización, íbamos constatando que los miembros de determinadas organizaciones colaboraban en las actividades de otras organizaciones.

\section{Fisuras y fraccionamientos: las plataformas estatales}

Una de las estrategias de actuación para tener éxito en el juego es crear alianzas con otros actores sociales. Las alianzas multiplican la capacidad de incidencia de los actores ante terceros. Cuando se trata de incidir sobre las administraciones públicas $\mathrm{u}$ otras entidades sociales que no son ONGD, las ONGD no tienen grandes dificultades en agruparse para constituir coordinadoras. Ahora bien, cuando analizamos el juego entre las mismas ONG, podemos comprobar que se construyen subgrupos para la defensa de sus intereses particulares. Estos subgrupos construyen significados que dotan de sentido estas pautas de agrupamiento, significados que fluyen a través de los canales internos de la red $y$, en ocasiones, afloran al exterior. A nivel estatal esto se produce de manera muy pronunciada: existe una marcada segmentación entre ONG «confesionales» (vinculadas a la Iglesia Católica) y ONG «progresistas», que afirman tener concepciones distintas de la solidaridad y el desarrollo. Esta segmentación se traduce en la creación de dos plataformas: la plataforma «REDES» (Red de Entidades para el Desarrollo Solidario) y la «Plataforma 2015 y más». Posiblemente, estas plataformas sean únicamente la punta visible del iceberg de la compleja trama de relaciones entre las ONGDs del estado. En Andalucía estas plataformas apenas tienen existencia, aunque existen delegaciones de algunas de sus organizaciones, ya que la integración y participación en ellas suele ser competencia de las sedes centrales.

El 8 de marzo de 2003, tuvo lugar la asamblea plenaria de constitución de la plataforma «REDES», compuesta por ONG ligadas a instituciones religiosas y otras organizaciones de inspiración cristiana que deseaban trabajar de forma conjunta. Para ello, establecieron un "Convenio marco" en el que recogen los principios en que se basan. Estas organizaciones afirman tener un estilo propio de cooperación y 
unas concepciones comunes del desarrollo, que provienen de los valores del Evangelio - plasmados en la Doctrina Social de la Iglesia- y de otras fuentes como los derechos humanos, la declaración del derecho al desarrollo, etc.

Las entidades que la conforman son ADECO (Amistad, Desarrollo, Cooperación), AMANI, AMSALA (Asociación Misionera Salvatoriana para Latinoamérica), Asociación Calasancio, Asociación Enrique de Ossó, Asociación PROYDE, Congregación Hermanas del Amor de Dios, Economía y Colaboración Solidaria (ECOSOL), Fundación Internacional de Solidaridad Compañía de María (FISC), Fraternidad Misionera S.C., Fundación PROCLADE Centro, GARERABIN, HAREN ALDE (Agustinos Recoletos), Hijos de María Inmaculada, Instituto de Hermanos del Sagrado Corazón, Instituto de Religiosas de San José de Gerona, Juan Ciudad, KARITSolidarios por la paz, Madreselva, Misión América, OCASHA. Cristianos con el Sur, PROCLADE Asturias, PROCLADE Bética, Religiosas Nuestra Señora de la Compasión y Asociación Solidaridad Vedruna (SOLIVE).

Por otro lado, la «Plataforma 2015 y más» se creó con el objetivo de aunar esfuerzos para cumplir con los «Objetivos de Desarrollo del Milenio» fijados por Naciones Unidas ${ }^{5}$ y coordinarse entre una serie de organizaciones que se identifican como laicas y «progresistas» (Bengoa, J. y Callejón, M. E., 2004). Está integrada por Acsur-Las Segovias, Arquitectos Sin Fronteras, Asamblea de Cooperación por la Paz, Consejo Español de Ayuda a los Refugiados (CEAR), Cooperació, Economistas Sin Fronteras, Fundación Paz y Solidaridad-CC.OO., Instituto de Estudio para América Latina y África (IEPALA), IPADE, Instituto Sindical de Cooperación al Desarrollo (ISCOD-UGT), Movimiento por la Paz, el Desarme y la Libertad (MPDL), Paz y Tercer Mundo-Mundu Bat y Solidaridad Internacional.

Han desarrollado actividades comunes como seminarios e informes anuales sobre los «Objetivos de Desarrollo del Milenio», stands conjuntos en jornadas solidarias y adoptar una posición común ante el conflicto en Palestina. Pretenden coordinarse también en temas relacionados con comportamientos los éticos de las ONG.

\footnotetext{
${ }^{5}$ Erradicar la extrema pobreza y el hambre, reduciendo a la mitad, entre 1990 y 2015 , la proporción de personas pobres; conseguir la educación primaria universal en el 2015; promover la igualdad de género y «empoderar» a las mujeres; reducir la mortalidad infantil en dos tercios, entre 1990 y 2015; mejorar la salud materna, reduciendo en tres cuartos la tasa de mortalidad materna; ampliar el acceso a la planificación familiar y combatir el VIH/SIDA, la malaria y otras enfermedades; garantizar la sostenibilidad medioambiental y reducir a la mitad la proporción de personas sin acceso a agua potable; y conseguir una Asociación Global para el Desarrollo que permita que los medicamentos y las nuevas tecnologías sean accesibles a los países en desarrollo.
} 
La constitución de esta red de organizaciones tuvo lugar bajo el mandato del Partido Popular, que favoreció a unas ONGD en detrimento de otras, las vinculadas o afines a los partidos, sindicatos e ideologías de izquierda. Fue, en parte, una reacción defensiva. Un informante lo explicaba así:

Esa plataforma se creó en un tiempo en que teníamos que estar a la defensiva, porque nos estaban tratando de aniquilar. Es decir, que era una época en la que nos estaban persiguiendo directamente (...) Por el gobierno (del Partido Popular). Nos retiraron muchas subvenciones, muchas organizaciones tuvieron que cerrar oficinas, despedir gente... (Informante $\mathrm{H}$, técnico de ONGD «progresista»).

\section{La Coordinadora Andaluza de ONGDs}

La Coordinadora Andaluza de Organizaciones No Gubernamentales (CAONGD) es una federación de ámbito regional sin ánimo de lucro, creada en 1993. Actualmente está integrada por 45 ONGD que tienen delegaciones en Andalucía. Su sede está ubicada en una zona céntrica de Sevilla.

Los principales objetivos con los que se crea son: coordinar las campañas y actividades realizadas por las ONGD miembros; crear lazos entre ONGD, movimientos sociales, administraciones municipales, diputaciones y Junta de Andalucía, en el ámbito de la cooperación para el desarrollo; sensibilizar a la opinión pública andaluza sobre las consecuencias negativas del actual modelo de desarrollo para los países en vías de desarrollo; y promover la investigación y la formación en materia de cooperación.

La estructura de la CAONGD se divide en órganos de gobierno (Asamblea General y Comité Ejecutivo) y órganos operativos (unidades operativas de coordinación o grupos de trabajo, comisión de seguimiento del código de conducta y el gabinete de asesoría técnica). La Asamblea General es el órgano supremo, está integrada por representantes de las ONGD asociadas (que deben llevar acreditación de su organización), invitados (con voz pero sin voto) y los miembros del Comité Ejecutivo. Está establecida una reunión ordinaria anual para aprobar la gestión del Comité Ejecutivo y diseñar las líneas generales de actuación para el periodo siguiente. Además, se pueden realizar asambleas extraordinarias a petición del Presidente del Comité Ejecutivo o de la tercera parte de las ONGD. Para que una asamblea sea considerada válida deben acudir al menos la mitad de las organizaciones integrantes. El orden del día y la notificación de la asamblea deben 
facilitarse con quince días de antelación. Las competencias de la Asamblea General, a grandes rasgos, son: ratificar la admisión o salida de nuevos miembros, establecer la cuantía de la cotización, aprobar o no el balance económico y la gestión del Comité Ejecutivo, revocar o elegir el Comité Ejecutivo, establecer las líneas generales de actuación, modificar los estatutos, decidir la disolución de la federación y solventar cuantas cuestiones sean incluidas en el orden del día a petición del Comité Ejecutivo o el treinta por ciento de las ONGD. Las decisiones habituales se toman por mayoría simple.

El Comité Ejecutivo está integrado por un Presidente, Vicepresidente, Secretario, Tesorero y los vocales de los diferentes grupos de trabajo. Se elige cada dos años. Una persona no puede permanecer en un mismo cargo más de cuatro años. Entre sus atribuciones destaca la dirección de la coordinadora, la gestión económica, la supervisión del GAT y la coordinación de los grupos de trabajo. Los grupos de trabajo actualmente son: acción humanitaria, cooperación descentralizada, educación para el desarrollo y género. Se reúnen periódicamente en la sede de la Coordinadora. En la actualidad, el presidente del Comité Ejecutivo es Nicolás de Alba Fernández (Solidaridad Don Bosco), el vicepresidente es José Antonio Hernández de Toro (Intermón Oxfam), el secretario José Luis Ayerbe Aguayo (Medicus Mundi-Andalucía), la tesorera May Ruiz de la Rosa (C.I.C. Batá), el vocal de acción humanitaria Miguel Castro Moreno (Asociación de Amistad con el Pueblo Saharahui-Sevilla), el vocal de cooperación descentralizada Héctor Rivero García (Solidaridad Internacional-Andalucía), el vocal de educación para el desarrollo Carlos Vela Pizarro (Madre Coraje) y la vocal de género Lourdes Medina Béjar (A.P.Y.-Solidaridad en Acción).

El Gabinete de Asesoría Técnica se encarga de asesorar a las ONGD federadas de las convocatorias de subvenciones, asesorarlas en la elaboración de sus proyectos de cooperación y educación para el desarrollo para que éstos logren financiación, formar a los miembros de las ONGD, facilitar las comunicaciones entre ONGD (por ejemplo, a través de un boletín electrónico semanal), etc. Lo integran 4 personas contratadas a tiempo completo: una Directora Técnica, una Responsable técnico de proyectos, una Responsable de comunicación y Responsable de administración. Este gabinete se creó por primera vez en el año 2000 mediante un Convenio entre la CAONGD y la Consejería de la Presidencia, el órgano de la Junta de Andalucía competente en materia de cooperación. En opinión de los informantes la creación de este gabinete responde a una estrategia de la Administración de externalizar ciertas tareas: 
...porque la Consejería de la Presidencia se quejaba mucho de que los proyectos no llegaban con suficiente calidad a las convocatorias y se pierde mucho tiempo en el trámite de subsanar (...) Y entonces ellos, en una especie como de estrategia de quitarse un poco el peso de encima, de hecho si tú hablas con la Consejería de la Presidencia, ellos piensan que el $90 \%$ de los objetivos del GAT es quitarle a ellos trabajo, que a ellos les lleguen los proyectos como filtrados. No como a contenido, sino en cuanto a forma: bien redactado, que no le falte ningún papel...Y así nació el Convenio del GAT (informante $\mathrm{F}$, técnico de la CAONGD).

En un primer momento el convenio duró dos años, y se contrataron tres personas. No se renovó hasta mayo de 2004. La ausencia de este gabinete, una vez creada la necesidad, contribuyó a generar una crisis importante en la Coordinadora.

...cuando eso desaparece, volver atrás fue un descontrol: se llama a la coordinadora y no hay nadie, llega el correo y no se mira, etc. En fin, la coordinadora en ese sentido desaparece un poco de la vida cotidiana de las ONGs, pues ya no existe el boletín que tenemos que mandar periódicamente, la coordinadora ya no informa de convocatorias, deja de ser ese pequeño referente de información y de formación que debe ser (informante $F$, técnico de la CAONGD).

En el 2004 se renueva el Convenio y se realiza una convocatoria de plazas para el GAT de la CAONGD. Se elaboran unos perfiles en que se exige cierta formación académica y experiencia profesional. Se busca la complementariedad de conocimientos y de carácter entre el personal. El el proceso de selección se creó una comisión mixta entre el Comité Ejecutivo y la Junta de Andalucía, aunque su presencia es testimonial.

La Comisión de Seguimiento del Código de Conducta se encarga de velar por el cumplimiento de las normas recogidas en el Código de Conducta de la Coordinadora, y de asesorar en estas cuestiones a las organizaciones federadas. Se reúne periódicamente y está compuesta por cinco miembros: el presidente de la CAONGD, dos representantes de las organizaciones federadas y dos personas ajenas a la coordinadora que tengan prestigio en el ámbito de la cooperación. Habitualmente se reúnen en el Centro Fe y Cultura Padre Arrupe que la Compañía de Jesús ofrece a muchas ONG y asociaciones para realizar sus actividades, o en el centro cívico "Las Sirenas" del Ayuntamiento. Las organizaciones federadas están obligadas a firmar el código de conducta. No obstante, esta comisión no vela por el 
cumplimiento del código. No se han dado casos de llamadas de atención y mucho menos de sanciones por incumplimiento. El código es más un compendio de reflexiones y recomendaciones, que un sistema de normas de obligado cumplimiento.

El artículo 4 de los estatutos de la CAONGD reza: "podrán pertenecer a esta Coordinadora aquellas Organizaciones No Gubernamentales que desarrollen su actividad en o desde Andalucía, que carezcan de vinculación institucional u orgánica con la Administración Estatal, Autonómica o Local, así como de finalidad lucrativa, tengan personalidad jurídica...". En el artículo 26 quedan establecidos los pasos que debe seguir una organización para hacerse miembro. En primer lugar, la ONGD debe presentar al Comité Ejecutivo una solicitud por escrito, el aval de dos organizaciones miembros, la memoria de actividades del año anterior, una copia de los Estatutos y un certificado de inscripción en el registro de asociaciones. Posteriormente, el Comité Ejecutivo podrá acordar el ingreso provisional de la organización solicitante, que será ratificada, o no, en la siguiente Asamblea General.

Formar parte de la coordinadora exige abonar las cotizaciones acordadas por la Asamblea General, a cambio, garantiza el derecho a participar en la toma de decisiones teniendo voz y voto en las Asambleas Generales y se accede los servicios del GAT, los más demandados son los de asesoramiento para el diseño de proyectos de desarrollo de cara a obtener financiación pública y los de apoyo en actividades de "EpD” (Educación para el Desarrollo). Aunque los miembros del GAT también atienden demandas de organizaciones no federadas. La financiación de la coordinadora se realiza principalmente a través del Convenio con la Consejería de la Presidencia y las cuotas de las organizaciones asociadas. Para actividades extraordinarias buscan subvenciones públicas, intentando no coincidir para no competir en las convocatorias con sus ONG federadas. Lo cual no siempre es posible.

Las ONGD son dadas de baja de la Coordinadora cuando se produce su disolución, cuando no cumplen sus obligaciones (principalmente pagar la cuota) o cuando lo deciden voluntariamente. 
Además de la CAONGD, en Andalucía hay varias coordinadoras provinciales o federaciones municipales de cooperación: Córdoba Solidaria, Foro Otro Mundo es Posible de Almería, Coordinadora de ONG de Granada, Málaga Solidaria o la Coordinadora Sevillana de ONGD. Estas federaciones son principalmente un espacio de encuentro entre las administraciones municipales y las ONG. Otro espacio de encuentro de estas características es el FAMSI (Fondo Andaluz de Municipios para la Solidaridad Internacional), una entidad privada sin ánimo de lucro, integrada por veinticinco ayuntamientos andaluces y algunas entidades colaboradoras. Financia proyectos de ONGD - de cooperación, ayuda humanitaria y educación para el desarrollo-, asesora a ONG y fomentar que las administraciones municipales se impliquen en la ayuda al desarrollo. Su sede está en Córdoba, fue creado en 1994 con el objeto de promover la «cooperación descentralizada».

\section{La CAONGD como arena política: facciones, significados y consecuencias prácticas}

De las 45 organizaciones que componen la CAONGD, hemos seleccionado las 30 más activas para facilitar el análisis. Hemos entendido que las más activas son aquellas que asisten regularmente a las asambleas y participan en los distintos grupos de trabajo. Éstas son las siguientes: Asamblea de Cooperación por la Paz $(\mathrm{ACpP})^{6}$, Asociación Espiritual Mundial "Brama Kumaris" (AEMBK), A.P.Y.Solidaridad en Acción, Asociación Andaluza por la Solidaridad y la Paz (ASPA), Ayuda en Acción (AeA), Ayudemos a un niño, Caravana por la Paz (CpP), Centro de Iniciativas para Cooperación-Batá (C.I.C.-Batá), Centro de Estudios y Solidaridad con América Latina (CESAL), Desarrollo Comunitario Internacional (DECCO), Educación Sin Fronteras (ESF), Entreculturas-Fe y Alegría (E-FyA), Fundación Internacional de Solidaridad Compañía de María (FISC), Ingeniería Sin Fronteras (ISF), Intermón Oxfam (IO), Jóvenes del Tercer Mundo (JTM), Madre Coraje (MC), Manos Unidas (MU), Medicus Mundi-Andalucía (MM-A), Movimiento por la Paz, el Desarme y la Libertad (MPDL), Médicos Sin Fronteras (MSF), Mujeres en Zona de Conflicto (MZC), Paz y Desarrollo (PYD), Paz y Solidaridad-Andalucía (PyS), PROCLADE Bética (PB), Promoción y Desarrollo (PROYDE), Servicio al Tercer Mundo (SETEM), Solidaridad Don Bosco (SDB), Solidaridad Internacional-Andalucía (SI-A) y UNICEF-Andalucía.

\footnotetext{
${ }^{6}$ Los acrónimos que mostramos entre paréntesis los hemos elaborado nosotros para identificar las organizaciones en la visualización de la red. Por lo tanto, pueden coincidir o no con los acrónimos reales de la ONGD.
} 
Preguntamos por diferentes vías -entrevista, correo electrónico y encuesta telefónica- a representantes de estas ONGDs con qué ONGDs implantadas en Andalucía habían trabajado conjuntamente (en proyectos, actividades formativas, de sensibilización, etc.), al margen de la CAONGD.

Con los resultados obtenidos hemos construido una matriz de modo $1,30 \times 30$, binaria - en la que " 1 " significa que existe relación estrecha y " 0 " que no existe relación estrecha- y asimétrica - ya que una organización puede afirmar haber trabajado con otra sin que la segunda señale haber trabajado con la primera. Debido a esto, hemos querido visualizar no sólo la existencia de un vínculo entre dos organizaciones - a través de una línea que las une en el grafos-, sino el sentido de ese vínculo - mediante una flecha apuntando a la ONGD reconocida-. En otras palabras, hemos registrado «relaciones dirigidas». Con la matriz construida, hemos visualizado la red con el programa Ucinet 6 (Borgatti, S.P., Everett M.G. y Freeman, L.C., 2002):

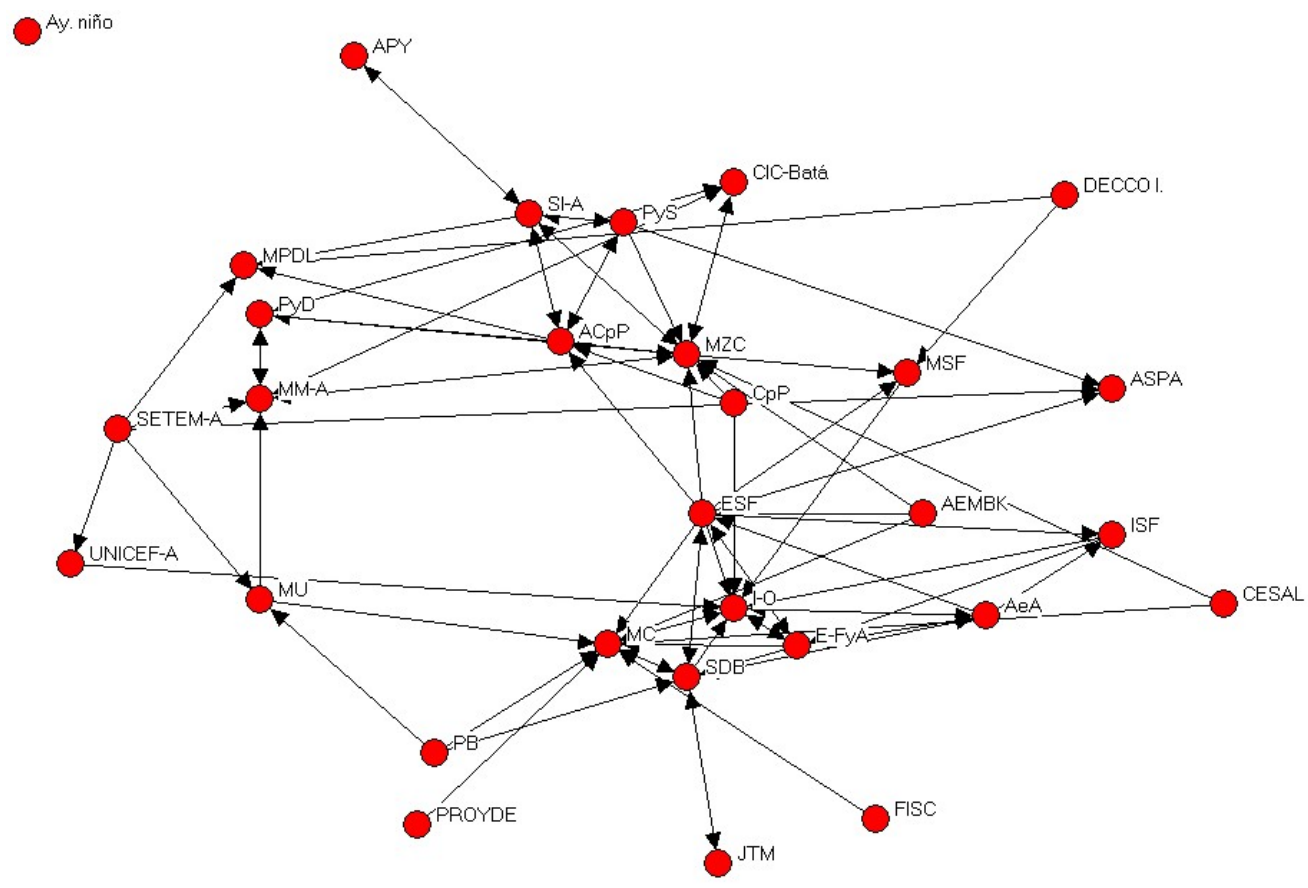


Posteriormente hemos coloreado las organizaciones según sus relaciones (orgánicas o ideológicas) con otras entidades sociales: de rojo las ONGD que se identifican como «progresistas», de verde las relacionadas con la I glesia Católica ${ }^{7}$ y de azul las demás, que podemos denominar «neutras». Éste ha sido el resultado:

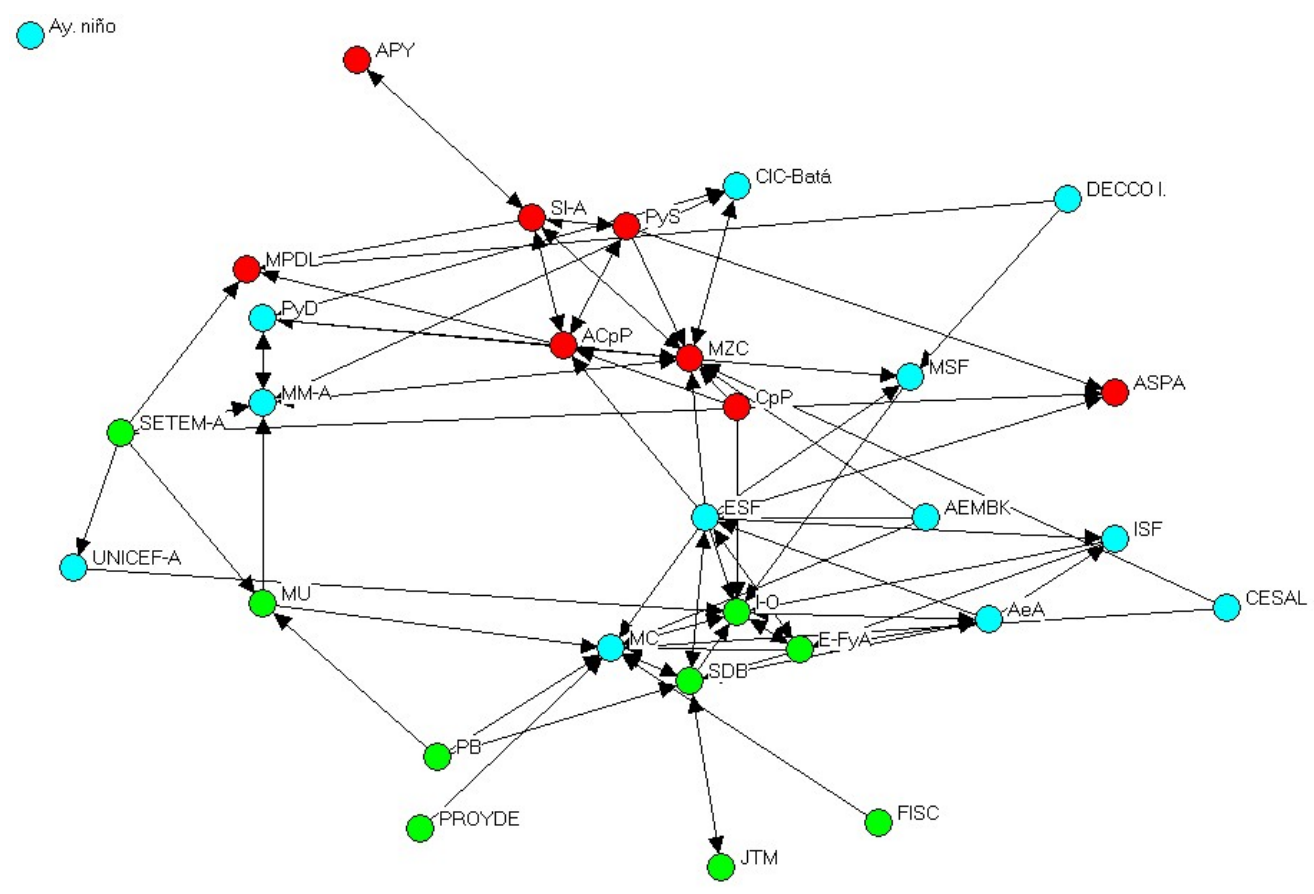

La visualización de las redes de relaciones entre ONGD confirma la fuerte fragmentación que padecen: en un extremo encontramos a las ONGD «progresistas» (rojo) y en el extremo opuesto a las «confesionales» (verde), entre medio, una multiplicidad de organizaciones con planteamientos más o menos izquierdistas y más o menos religiosos. Resulta significativo que aunque el grupo intermedio (azul) es el más numeroso, los cargos directivos de la coordinadora están copados por miembros de los otros dos subgrupos, lo cual nos indica que la coordinadora es un espacio de poder, una arena política. El subgrupo verde, mayor numéricamente que el rojo, ocupa en la actualidad los cargos más importantes de la coordinadora (presidencia y vicepresidencia, además de la vocalía de educación para el desarrollo). El subgrupo rojo tan sólo ocupa dos vocalías.

Finalmente, incluimos el atributo "provincia de implantación de la sede central en Andalucía de la ONGD” para comprobar si la ubicación geográfica de las sedes está

\footnotetext{
${ }^{7}$ Dentro de este grupo he incluido a Intermón Oxfam, que no calificaríamos de «confesional», aunque su Patronato esté integrado en un $30 \%$ por miembros de la Compañía de Jesús, y a Madre Coraje, que no es una ONG confesional pero la mayoría de sus miembros son católicos y su estilo de cooperación se acerca en gran medida al modelo asistencial [sobre modelos de cooperación ver (Ortega, 1994)].
} 
relacionada con este conflicto. Hemos representado Sevilla con un círculo, Córdoba con un rombo, Cádiz con un diamante, Almería con un cuadrado, Granada con un triángulo hacia arriba y Málaga con un triángulo hacia abajo (ninguna de las ONGD seleccionadas tiene su sede central en Huelva ni Jaén).

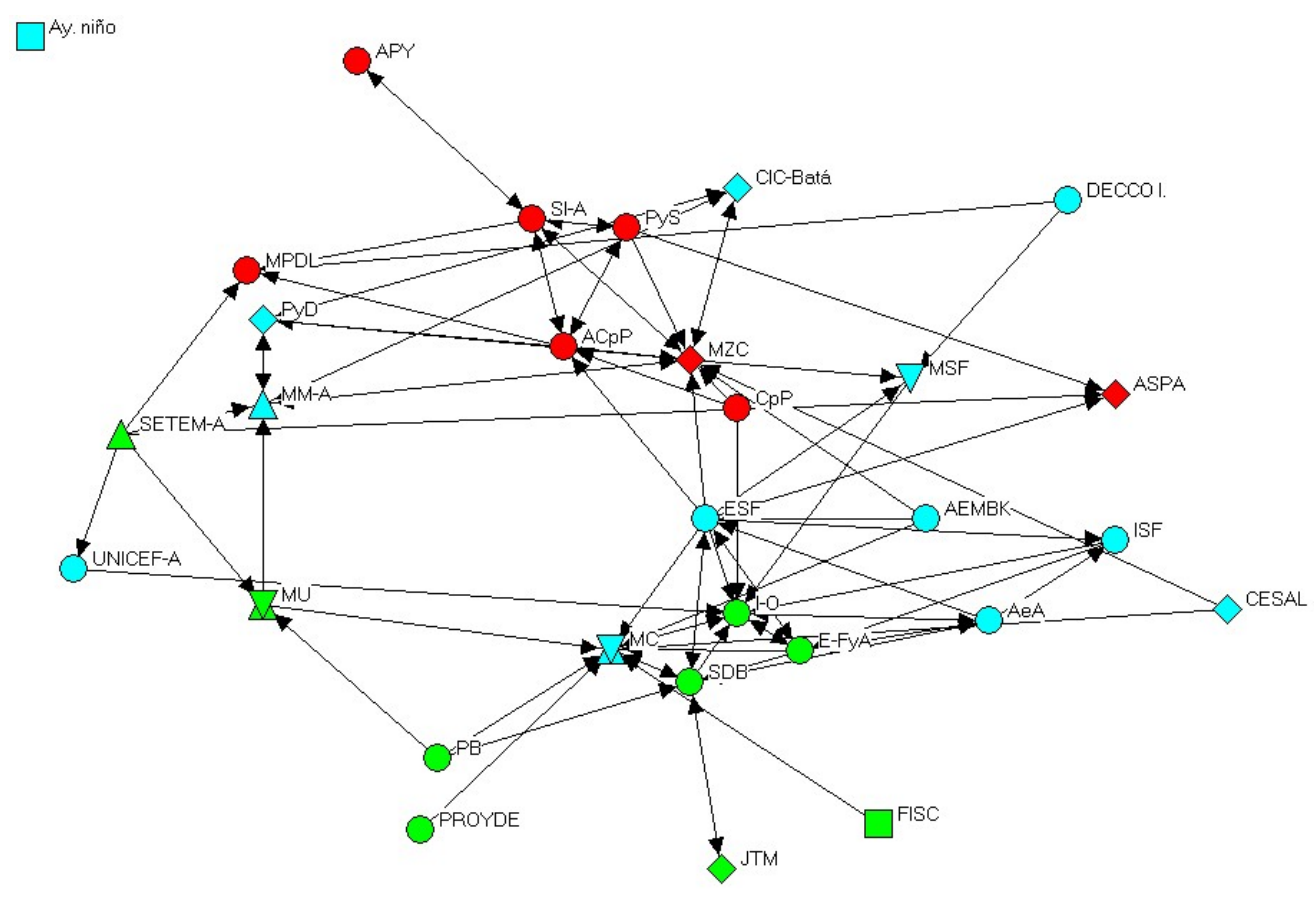

La localización de la sede de las organizaciones en la geografía andaluza es una variable central en la articulación de estas redes. La fundación Ayudemos a un niño no tiene vínculos las demás organizaciones, pues su sede está en Almería. Curiosamente, las organizaciones «progresistas» y «confesionales» más involucradas en el conflicto tienen sus sedes centrales en Sevilla. En cambio, un buen número de las organizaciones que se mantuvieron en un plano secundario tienen sus sedes en Córdoba, Granada y Málaga (SETEM, ASPA, Medicus Mundi, Médicos Sin Fronteras, ClC-Batá).

A pesar de constatar esta fragmentación en base a las creencias de las ONGD, conviene realizar algunas matizaciones. Es cierto que las ONGD «progresistas» tejen su red en función de la variable ideológica, y así lo explicitaron los informantes entrevistados. En su opinión, la Iglesia Católica debería estar al margen de la cooperación. Sin embargo, el bloque que he denominado ONGD «confesionales» no es propiamente tal. Más bien existe una facción de redes muy densas formada por las organizaciones: Solidaridad Don Bosco, Entreculturas-Fe y Alegría, Madre Coraje, Ayuda en Acción, Educación Sin Fronteras e Intermón Oxfam. Entre estas entidades hay tres sin vínculos orgánicos con la Iglesia Católica 
(Madre Coraje, Ayuda en Acción y Educación Sin Fronteras) y una (Intermón Oxfam) que nació como ONG de la Compañía de Jesús, pero ésta perdió cierta influencia en sus órganos de gobierno tras la incorporación a la federación Oxfam International en 1997. Las relaciones estrechas entre estas organizaciones tienen que ver con unas concepciones más o menos homogéneas de la cooperación al desarrollo, pero también con amistades personales ${ }^{8}$, muchas de ellas surgidas a raíz de ser compañeros en el master de cooperación al desarrollo organizado por ETEA - la institución universitaria de la Compañía de Jesús- donde se ha formado un gran número de profesionales de este área. Un informante lo explicaba así:

Hay otras ONG a las que no llamas nunca, yo personalmente no las llamaría jamás. Y a la hora de cooperar con ellas pues... yo creo que no llevaría proyectos de cooperación con ellas. Porque no me dan confianza, porque son muy personalistas, por ejemplo (...) Muchas de las ONG que nos llevamos bien es porque nos conocemos el personal: porque hemos estado en un master juntos, porque hemos hecho trabajos juntos (...) Yo diría más bien, eso es una opinión muy personal, que hay las ONG que nos gusta involucrarnos e involucrar a otras en nuestros procesos, y hay ONG que les gusta permanecer aisladas (...), hay ONG que sienten que involucrarse con otros es perder espacios de poder (...) se auto-aíslan pues por el dichoso poder (Informante $B$, técnico de ONGD confesional).

El mismo informante explica que esta polarización está causada por ONGD que manifiestan cierta animadversión hacia las ONGD vinculadas a la I glesia Católica.

Hay determinadas ONG laicas que por sistema tienen un rechazo a las organizaciones vinculadas con la Iglesia, porque identifican con evangelización. Nosotros no hacemos evangelización, no, nosotros no vamos por la vida predicando la palabra de Dios y esas cosas, a nosotros no nos mueve eso como organización. ¿Que nos mueve un impulso cristiano? Sí, no lo negamos, es que está en nuestros papeles, no está oculto. Entonces, hay mucha gente que dice, hay ONG de la iglesia. Entonces se auto-aíslan (Informante B, técnico de ONGD confesional).

Esta fragmentación interna de la CAONGD no impide un funcionamiento fluido, las relaciones ordinarias entre ONGD son cordiales y cooperativas. Organizaciones de

\footnotetext{
8 Dejamos pendiente la realización de un análisis detallado de las relaciones de amistad entre los representantes de las ONGD y la relevancia de esta variable en la configuración de la red.
} 
diferentes corrientes trabajan juntas dentro de los grupos de trabajo y las asambleas transcurren sin incidentes. No obstante, algunos informantes han declarado haber vivido algunas situaciones de tensión en determinados momentos críticos. En algunas ocasiones esta segmentación puede originar conflictos entre ellas que interfieran en el desarrollo de las actividades conjuntas. En concreto en el periodo que va de febrero 2003 a mayo de 2004 hubo una fuerte crisis en la Coordinadora de la que la desaparición del GAT fue sólo un factor secundario. Por aquél entonces se iba a aprobar la Ley Andaluza de Cooperación después de un proceso mucho más largo del que se había comprometido la administración en el Pacto Andaluz por la Solidaridad. La administración invitó a la Coordinadora a participar formulando propuestas y enmiendas. El Comité Ejecutivo de aquel momento decidió que la Coordinadora no iba a proponer enmiendas. De las organizaciones que lo componían -SI, ACpP, IO, AEBK, ISF, MSF, MZC, etc.- todas menos ISF consideraron suficientes las enmiendas propuestas por otros partidos políticos. En ese momento surge un fuerte conflicto interno en la Coordinadora, pues muchas organizaciones -incluidas algunas que formaban parte del Comité ejecutivo y tomaron la decisión- estaban descontentas. A partir de entonces se empieza a cuestionar la legitimidad del Comité Ejecutivo:

...un lío de correos electrónicos que empezaron a pulular por las ONG (...) entonces empieza a haber un movimiento paralelo o clandestino, de algunas ONG que querían un poco como darle un vuelco a la coordinadora (informante $C$, técnico de ONGD «neutra»).

Este enfrentamiento abierto no fue más que el afloramiento de las divisiones y las luchas intestinas del campo de la coopeación, que subyacen a las relaciones entre ONGD. El presidente de la CAONGD en ese momento era el presidente de Solidaridad Internacional-Andalucía - ONGD que es percibida desde el exterior como una "ONG del PSOE"-, que fue elegido presidente de la Coordinadora con pocos apoyos.

...eso era sólo la punta de un iceberg, de gente que se dudaba de su neutralidad. De hecho, en otras coordinadoras autonómicas corría el rumor de que la coordinadora andaluza estaba muy politizada. Porque la realidad es que, independientemente de valoraciones subjetivas, Manuel Martínez Ocón era, y es supongo, una persona del PSOE (...) de hecho, él fue elegido por muy pocos votos, la mitad o así, el resto se abstuvieron. $Y$ al principio dijo que dimitía porque no se sentía respaldado, pero luego se lo pensó mejor, 
pensó que iba a ser un caos abandonar la presidencia y se quedó en el cargo (informante $C$, técnico de ONGD «neutra»).

El presidente de la ONGD en cuestión ha dejado claro que su organización no pertenece al PSOE, aunque sí considera que SI-A es una organización laica y de izquierdas:

(...) es verdad que alguna gente por fuera nos tildan que somos del PSOE, no es verdad. Somos completamente autónomos, no tenemos ninguna relación orgánica con el PSOE. Pero es verdad que hay un sentimiento entre comillas de que nos podemos considerar de la izquierda laica de España. Entonces, no tenemos ningún apoyo, pero la gente nos conoce porque defendemos los valores históricos de los derechos humanos, los derechos de los trabajadores, etc. Además nos sentimos un poquín identificados, un poquín no, bastante identificados con la lucha de lo que ha sido el movimiento obrero internacionaL (Presidente de SI-A).

Finalmente, Tras el desagradable conflicto, el Comité Ejecutivo dimitió y se eligió al actual, cuya composición se corresponde más con las correlaciones de fuerzas entre las distintas corrientes.

\section{Análisis de las medidas de centralidad de la red}

La centralidad de una ONGD dentro de una red conlleva un mayor control de información, menor tardanza en la llegada u obtención de esa información, más apoyos en los procesos de toma de decisiones, mayor capacidad para ocupar los cargos de representación en la federación, etc. La red de relaciones de una persona u organización constituyen una importante fuente de poder o capital (social). Este poder relacional depende de la centralidad del sujeto en cuestión dentro de la red, lo que se puede medir en función de diversas variables complementarias.

A partir del sociograma podemos analizar la centralidad de los actores utiliando tres indicadores contrastables entre sí: el rango (degree), el grado de intermediación (betweenness) y la cercanía (closeness). El rango es el número de nodos con las que un nodo está conectado, es decir, el número de organizaciones con las que declara haber trabajado una organización y el número de organizaciones que dicen trabajar con ella. 


\begin{tabular}{|l|c|c|c|c|}
\hline ESF & OutDegree & I nDegree & NrmOutDegree & NrmI nDegree \\
MZC & 9 & 4 & 31,034 & 13,793 \\
AeA & 6 & 10 & 20,69 & 34,483 \\
SETEM-A & 5 & 2 & 17,241 & 6,897 \\
SI-A & 5 & 0 & 17,241 & 0 \\
E-FyA & 5 & 4 & 17,241 & 13,793 \\
ACpP & 5 & 4 & 17,241 & 13,793 \\
PyS & 5 & 5 & 17,241 & 17,241 \\
SDB & 4 & 2 & 13,793 & 6,897 \\
PB & 4 & 6 & 13,793 & 20,69 \\
PyD & 3 & 0 & 10,345 & 0 \\
AEMBK & 3 & 4 & 10,345 & 13,793 \\
CIC-Batá & 3 & 0 & 10,345 & 0 \\
MM-A & 3 & 3 & 10,345 & 10,345 \\
CpP & 3 & 5 & 10,345 & 17,241 \\
CESAL & 3 & 0 & 10,345 & 0 \\
MU & 2 & 0 & 6,897 & 0 \\
DECCO I. & 2 & 2 & 6,897 & 6,897 \\
I-O & 2 & 0 & 6,897 & 0 \\
ISF & 2 & 9 & 6,897 & 31,034 \\
MC & 2 & 2 & 6,897 & 6,897 \\
PROYDE & 2 & 9 & 6,897 & 31,034 \\
MSF & 1 & 0 & 3,448 & 0 \\
FISC & 1 & 3,448 \\
APY & 1 & 1 & 3,448 & 3,448 \\
JTM & 1 & 3,448 & 0,348 \\
UNICEF-A & 1 & 3,448 & 3,448 \\
Ay. niño & 0 & 0 & 0 & \\
ASPA & 0 & 3 & 0 & 0 \\
\hline
\end{tabular}

La ONGD que afirma trabajar con más organizaciones es Educación Sin Fronteras con un rango de 9 -y un rango normalizado, es decir, el porcentaje de conexiones sobre toda la red, del 31,034\%. Después le sigue un grupo de 8 organizaciones que declaran trabajar con entre 4 y 6 organizaciones. El resto (21 organizaciones) presenta un rango entre 0 y 3 . Sin embargo, el número de homólogas con que afirma trabajar una ONGD no siempre coincide con el número de organizaciones que alegan trabajar con esa ONGD. Esta limitación en el análisis reticular puede explicarse por el hecho de que la importancia atribuida al trabajo con otras organizaciones depende de la antigüedad y reconocimiento social de la ONGD. Las ONGD más mencionadas son Mujeres en Zona de Conflicto, con un rango de 10, Intermón Oxfam y Madre Coraje, ambas mencionadas 9 veces. Hay que resaltar que SETEM, Proclade Bética, Brahma Kumaris, Caravana por la Paz, CESAL, DECCO Internacional, PROYDE, FISC-Compañía de María y Ayudemos a un niño, no fueron mencionadas como colaboradora por ninguna organización. Detectamos, por tanto, unas débiles relaciones entre las ONGD implantadas en Andalucía. A pesar de ser mencionadas 9 veces, Intermón y Madre Coraje sólo mencionaron a dos ONGD 
cada una como colaboradoras. En un primer momento barajamos la posibilidad de que esta diferencia entre mencionar y ser mencionado podría explicarse en base al tamaño de la ONGD, pensamos que las ONGD más grandes (número de socios, implantación territorial, etc.) podían ser más propensas a ser mencionadas en la entrevista. No obstante, los resultados obtenidos desechan esta hipótesis puesto que Mujeres en Zona de Conflicto y Madre Coraje son ONGD medianas y básicamente de ámbito andaluz.

El grado de intermediación (betweenness) es la frecuencia con la que una ONGD aparece en el tramo más corto que conecta a dos organizaciones. Las organizaciones con un mayor grado de intermediación son Mujeres en Zona de Conflicto $(168,833)$, Educación Sin Fronteras $(151,667)$ e Intermón-Oxfam $(136,500)$. Lamentablemente, 15 organizaciones tienen un grado de intermediación de 0 . Por su parte, Madre Coraje, a pesar de su alto rango, presenta un grado de intermediación medio $(56,833)$.

\begin{tabular}{|l|c|c|}
\hline MZC & Betweenness & nBetweenness \\
ESF & 168,833 & 20,792 \\
I-O & 151,667 & 18,678 \\
SDB & 136,5 & 16,81 \\
MSF & 95 & 11,7 \\
E-FyA & 81 & 9,975 \\
ACpP & 70 & 8,621 \\
AeA & 63,833 & 7,861 \\
MC & 57,333 & 7,061 \\
SI-A & 56,833 & 6,999 \\
MM-A & 52 & 6,404 \\
PyS & 20,167 & 2,484 \\
MU & 8,667 & 1,067 \\
UNICEF-A & 7,5 & 0,924 \\
PyD & 4,667 & 0,575 \\
DECCO I & 1 & 0,123 \\
AEMBK & 0 & 0 \\
APY & 0 & 0 \\
ASPA & 0 & 0 \\
MPDL & 0 & 0 \\
Ay. Niño & 0 & 0 \\
CPP & 0 & 0 \\
JTM & 0 & 0 \\
CIC-Batá & 0 & 0 \\
PB & 0 & 0 \\
PYODE & 0 & 0 \\
SETEM-A & 0 & 0 \\
\hline
\end{tabular}




\begin{tabular}{|l|l|l|}
\hline FISC & 0 & 0 \\
ISF & 0 & 0 \\
CESAL & 0 & 0 \\
\hline
\end{tabular}

El grado cercanía refleja la cercanía de una ONGD al resto de la red, es decir, la capacidad de una ONGD de entrar en contacto con todas las demás. El grado de cercanía puede no coincidir con las otras medidas de centralidad (rango y grado de intermediación): el número de relaciones es importante, pero también la “importancia" de aquellas organizaciones con la que se está relacionado.

\begin{tabular}{|l|c|c|}
\hline ASPA & inCloseness & outCloseness \\
I-O & 20,714 & 3,333 \\
MPDL & 20,567 & 7,552 \\
MZC & 20,423 & 3,333 \\
MSF & 19,595 & 7,754 \\
ACpP & 18,954 & 7,268 \\
E-FyA & 18,71 & 7,592 \\
MC & 17,901 & 7,859 \\
AeA & 17,901 & 7,552 \\
MM-A & 17,576 & 7,859 \\
SDB & 17,576 & 7,455 \\
PyD & 17,365 & 7,838 \\
CIC-Batá & 17,16 & 7,455 \\
SI-A & 17,262 & 7,455 \\
ESF & 17,16 & 7,592 \\
PyS & 16,763 & 8,101 \\
ISF & 16,292 & 7,572 \\
JTM & 15,934 & 7,552 \\
APY & 15,183 & 7,494 \\
MU & 14,948 & 7,268 \\
UNICEF-A & 3,571 & 8,215 \\
Ay. niño & 3,448 & 7,775 \\
DECCO I & 3,333 & 3,333 \\
AEMBK & 3,333 & 7,572 \\
PB & 3,333 & 8,529 \\
PROYDE & 3,333 & 8,923 \\
SETEM-A & 3,333 & 7,775 \\
FISC & 3,333 & 9,898 \\
CpP & 3,333 & 7,775 \\
CESAL & 3,333 & 8,455 \\
\hline
\end{tabular}

Como muestra la figura anterior ASPA, Intermón Oxfam y MPDL son las organizaciones con mayor grado de cercanía (con algo más de 20 puntos). No obstante, ASPA y MPDL presentan un bajo rango (los menores) y un bajo grado de intermediación (los menores, 0). Esta diferencia se explica porque las pocas organizaciones con las que están relacionadas, a su vez, con muchas organizaciones, de tal suerte que tienen una mayor accesibilidad a todos los nodos de la red. Por otro lado, un grupo de 16 organizaciones presenta un grado de 
cercanía "medio" (entre 15 y 20 puntos), y el resto - las 11 organizaciones peor relacionadas- presenta un promedio de 3 puntos.

Como conclusión del análisis de las medidas de centralidad, podemos resaltar el escaso trabajo conjunto entre ONGD implantadas en Andalucía. Con excepción de las dos facciones encontradas, en conjunto existen unos lazos muy débiles. Un gran reto para la CAONGD será buscar fórmulas para el reforzamiento de los lazos, lo que necesariamente llevará a cuestionar su funcionamiento tan centralizado en Sevilla. Pero, posiblemente, sean las "reglas del juego" del campo de la cooperación no-gubernamental la principal causa de esta disfuncionalidad. En este espacio social predomina la competición sobre la cooperación. Las soluciones a esta encrucijada son extremadamente complejas, requeriría transformaciones radicales en el modelo de financiación de las ONGD, que no parece que se vayan a producir en el corto plazo.

Otra conclusión es que las organizaciones más prestigiosas y veteranas son una referencia para las organizaciones jóvenes o periféricas, puesto presentan una mayor tendencia a ser reconocidas como colaboradoras.

\section{Mostrando el sociograma ante los implicados}

Los participantes de las ONGD se muestran muy interesados en conocer investigaciones y reflexiones sobre sus actividades. Este análisis de redes interorganizacionales ha despertado formidablemente su curiosidad. Casi todo el que ha sabido que lo estabamos realizando nos han pedido que le facilitasemos en su momento los resultados finales, incluso nos han llegado a solicitar algunos avances.

Una vez construido el sociograma de la red de relaciones entre las ONGD andaluzas, lo mostramos a varios implicados en la problemática con el objeto de recoger sus impresiones. La totalidad de los actores que han visto el sociograma lo han visto correcto en términos generales. Consideran que es un reflejo fidedigno de la realidad.

Sin embargo, una informante nos hizo un comentario que nos ha revuelto de manera considerable: "esto no es exactamente lo que nosotros entendemos por «red»". Efectivamente, el significado que los académicos atribuimos a los conceptos que acuñamos no siempre es equivalente al que utilizan otros actores sociales. Para los participantes de las ONGD "red" equivale a "alianza", en cambio, para los científicos sociales "red" hace referencia a un conjunto de relaciones independientemente del contenido de éstas: familiares, cooperativas, conflictuales, 
etc. Existe, por tanto, por parte de los actores sociales, una apropiación de los conceptos construidos por los científicos sociales que entorpece el entendimiento mutuo entre el mundo académico y el exterior. Además, en ocasiones los conceptos distorsionados se filtran al mundo académico desde el exterior -y viceversa-, pudiendo llegar a extremos en los que las definiciones llegan a ser tan imprecisas que la validez de estos conceptos se ve seriamente cuestionada. Este es el caso, por ejemplo, con el concepto de «sociedad civil» (Roitter, 2004). En esos casos asistimos a auténticas luchas de significados. Puede que al término «red social» le esté ocurriendo algo de eso.

\section{Conclusiones}

A lo largo del artículo hemos tratado de describir y explicar las complejas y contradictorias relaciones entre las ONGD implantadas en Andalucía.

A partir del análisis de las redes inter-organizacionales de las ONGD hemos detectado la fuerte fragmentación entre «progresistas» y «confesionales» que padecen. Frente a terceros las ONGD tratan de ofrecer na imagen unitaria y coherente, se federan y construyen alianzas. Sin embargo, las interacciones entre ellas son más conflictivas, existe una auténtica lucha de poder. En esta lucha, la ideología es la que articula las alianzas: la confesionalidad y la independencia de partidos políticos son los motivos por los que manifiestan enfrentarse. Pero la competición entre organizaciones va más allá de la ideología: el poder en sus múltiples especies (socios, subvenciones, voluntarios, prestigio, donaciones, redes sociales, etc.) es el objetivo último.

Por otro lado, el análisis de las medidas de centralidad pone de manifiesto el escaso trabajo conjunto entre muchas ONGD. Esto se debe posiblemente a las "reglas del juego" del campo. A pesar de todo, el buen funcionamiento de la CAONGD constituye un auténtico reto que parecen estar consiguiendo en la actualidad. El reforzamiento de las coordinadoras provinciales y la participación conjunta en campañas de presión política, como la campaña “Pobreza Cero", van esa dirección.

Finalmente, al mostrar el sociograma elaborado a los informantes, nos dimos cuenta de que lo que los actores sociales entienden por red no coincide exactamente con el significado que los científicos sociales le hemos atribuido. 


\section{Agradecimientos}

Este trabajo no habría sido posible sin la colaboración y la amabilidad de todos aquellos responsables de ONGD que, a pesar de sus ingentes cargas de trabajo, se han prestado a ser entrevistados o a responder la encuesta. El equipo técnico de la CAONGD también me ha prestado todo su apoyo. Finalmente, reconocer las aportaciones de mis directores de tesis Isidoro Moreno Navarro y Félix Talego Vázquez y las sugerencias del profesor Elías Zamora Acosta.

\section{Bibliografía}

Bengoa, J. y Callejón, M. E. (coords.) (2004). Plataforma 2015 y más. La palabra empeñada. Los objetivos 2015 y la lucha contra la pobreza. Madrid: Catarata.

Borgatti, S.P., Everett, M.G. y Freeman, L.C. (2002). UCINET 6 for Windows. Software for Social Network Analysis. Harvard: Analytic Technologies.

Bourdieu, P. (1991). El Sentido Práctico. Madrid: Taurus.

Castells, M. (2000). La era de la información. Economía, sociedad y cultura. Vol 2. El poder de la identidad. Alianza, Madrid.

Freeman, Linton C. (2000). "Visualizing Social Networks". Journal of Social Structure, vol. 1, no 1 .

Fundación Lealtad (2003). Informe 2003. Intermón Oxfam. En http://www.fundacionlealtad.org/web/jsp/frames.jsp?3|1|jsp/organizaciones/listaO rganizaciones

Maffesoli, M. (1990.) El tiempo de las tribus: el declive del individualismo en las sociedades de masas. Icaria, Barcelona.

Michels, R. (1996). Los partidos políticos: un estudio sociológico de las tendencias oligárquicas de la democracia moderna. Amorrortu, Buenos Aires.

Molina, J. L. (2001). El análisis de redes sociales. Una introducción. Barcelona: Bellaterra.

Ortega Carpio, M. L. (1994). Las ONGD y la crisis del desarrollo. Un análisis de la cooperación con Centroamérica. Madrid/Córdoba: IEPALA/Publicaciones ETEA.

Panebianco, A. (1990). Modelos de partido. Organización y poder en los partidos políticos. Alianza Editorial, Madrid.

Perrow, C. (1961). "The Análisis of Goals in Complex Organizations", en American Sociological Review, no 5, pp. 854-866.

Roitter, M. (2004). “El tercer sector como representación topográfica de sociedad civil", en Daniel Mato (coord.) Políticas de ciudadanía y sociedad civil en tiempos de globalización. Caracas: FACES, Universidad Central de Venezuela, pp. 17-32.

Salomon, L., Anheier, H. K. y colaboradores (1999). La sociedad civil global. Las dimensiones del sector no lucrativo. Proyecto de estudio comparativo de la Universidad John Hopkins. Fundación BBVA, Bilbao. 